Association for Information Systems

AIS Electronic Library (AISeL)

ICEB 2003 Proceedings

International Conference on Electronic Business

(ICEB)

Winter 12-9-2003

\title{
A Methodology for Developing an Integrated Supply Chain \\ Management System
}

Yi-chen Lan

Follow this and additional works at: https://aisel.aisnet.org/iceb2003

This material is brought to you by the International Conference on Electronic Business (ICEB) at AIS Electronic Library (AISeL). It has been accepted for inclusion in ICEB 2003 Proceedings by an authorized administrator of AIS Electronic Library (AISeL). For more information, please contact elibrary@aisnet.org. 


\title{
A Methodology for Developing an Integrated Supply Chain Management System
}

\author{
Yi-chen Lan \\ School of Computing and Information Technology \\ University of Western Sydney \\ Australia \\ yichen@cit.uws.edu.au
}

\begin{abstract}
Integrated Supply Chain Management (ISCM) involves the linking of suppliers and customers with the internal supply processes of an organisation. ISCM solutions allow organisations to automate workflows concerning the execution and analysis of planning, sourcing, making, delivering, returns handling and maintenance. Many of today's ISCM systems use primarily web technology as the supporting infrastructure. Undoubtedly, the electronic (Internet-based) ISCM systems deliver the enterprises with a competitive advantage by opening up opportunities to streamline processes, reduce costs, increased customer patronage and more thorough planning abilities. However, there has been significant customer backlash concerning the inability of software vendors to deliver easy integration and promised functionality. Although various researchers have suggested strategies to overcome some of the failures in operating ISCM systems, there was a lack of architectural investigation in the analysis stage. The methodology proposed seeks to resolve these gaps and provides a fundamental framework in analysing ISCM systems.
\end{abstract}

\section{Introduction}

Please follow the formatting guidelines carefully. Papers should be prepared in conformity with this instruction sheet. If you have any questions, please contact with the organizer of ICEB2003.

The evolution of Internet technology has enabled enterprises in operating inter-organisational activities efficiently. Given the cost of logistics and its importance in order fulfilment process, organisations may take this opportunity to reengineer their supply chain operations to sustain in the global competitive challenge. With this invigorated growth of e-business, software vendors and consultants have promised the Internet-based supply chain systems, which provide businesses with the capability to respond in real-time in changing product demand and supply, and offer an easy integration functionality with backend information systems [15] [19].

Although a number of Internet-based supply chain systems (or integrated supply chain management systems - ISCM systems) are available for adoption, enterprises are not guaranteed to implement the systems in conjunction with their existing information systems. Furthermore, the ISCM systems may not fulfil the connection and implementation requirements between participants in the supply chain.

After the e-commerce hype had dissipated, surveys undertaken in 2001 tend to paint a different picture as to the success of these implementations. Smith [17] concludes that at least $15 \%$ of supply chain system implementations during 2001 and 2002 were abandoned in the US alone. Although several reasons can be identified as the cause of implementation failure, the main problem rests on the fundamental analysis of ISCM operations and requirements.

The purpose of this paper is to debunk some myths proposed by vendors with regards to the implementation of Integrated Supply Chain Environments (ISCE) and propose an analysis methodology for Integrated Supply Chain Management systems.

Firstly, the paper will examine some of the available literature regarding ISCE. The fundamentals of ISCE technologies and processes, will be investigated in some detail. Vendors were quick to promote the benefits of ISCE, yet were not so forthcoming as to possible barriers and other issues to watch for. Both of these will also be discussed in this paper.

Secondly, an analysis methodology is proposed, which intends to address some of the issues identified previously, and construct a theoretical model for enterprises to adopt in the analysis phase of developing ISCM systems. This paper concludes with a future research direction in investigating technological issues of ISCM systems operation.

\section{Integrated Supply Chain Management Overview}

ISCM involves the linking of Suppliers and Customers with the internal supply processes of an organisation. Internal processes would include both vertically integrated functional areas such as materials, sales and marketing, manufacturing, inventory and warehousing, distribution or perhaps, other independent companies, which involved in the supply chain (ie. channel integration). Customers at one end of the process can potentially be a supplier downstream in the next process, ultimately supplying to the end user [9] [19].

\subsection{ISCM solutions}

Whilst ISCM systems, in many cases are still in its infancy, the concept of establishing information flows between points in the supply chain has been around since the 1980's. Through Electronic Data Interchange (EDI), 
customers and suppliers have communicated supply data through direct dial-up interfaces and other mediums [21]. However, the ability for the Internet to create a common communication infrastructure has made integration much more cost-effective. Hence, ISCM has the ability to deliver the right product to the right place at the right time and at the right price.

From the supply chain software development perspective, there are generally 4 large vendors identified, which namely Oracle, SAP, PeopleSoft and Ariba and a multitude of medium-sized vendors in the ISCM solution space [2]. All claim that ISCM will enable the enterprise to respond, in real time, to changes in demand and supply.

For instance, current ISCM solutions allow organisations to automate workflows concerning the execution and analysis of the following business activities [8] [15].

1. Planning: demand \& supply planning, manage planning infrastructure

2. Sourcing (buy-side) - strategic sourcing, eprocurement, services procurement, catalog management, collaborative contract / supply management, esettlements / vendor payments

3. Making (in-side) - product lifecycle management, demand planning, production management, production planning, flow production, event management

4. Delivering (sell-side) - inventory, order management, promotions management, warehouse management, transportation management, delivery infrastructure management, ebill payment, scm portal

5. Returns handling (from customers)

6. Maintenance

\subsection{ISCM systems architecture}

Turner [19] quoted that information systems would be the enabler of integrated logistics. Armstrong [2] affirms that Turner's view has come to fruition. Many of today's ISCM systems use primarily web technology as the supporting infrastructure [6]. It is not uncommon in these instances, to develop a 3-tier or n-tier network architecture in order to provide robust support for ISCM systems.

For example, Advanced Software Design Inc. [1] illustrated the 3-tier ISCM integration architecture (Figure 1) in use by the US Department of Defence (DoD). Suppliers and customers alike, access the DoD ISCM through the use of Web portals (the 1st tier of the ISCM). Web portals provide the necessary web services to establish a common Graphical interface for the DoD's stakeholders in accessing supply chain data. Customers, suppliers, distributors and delivery agents can all access custom information and services supplied by the ISCM. Supplier services could include access to business-to-business (B2B) marketplaces, support and other push/pull supplier functionality. Alternately, customers can customise the site in order to access catalogues from the organisation and external suppliers, customer transaction details and other product, customer and technical support.

The portals are supported by messaging infrastructure (2nd tier), which provides the link to the underlying applications layer (3rd tier). The applications layer is independent of any particular interface (eg. portals) and contains the necessary business logic and data access in order to perform operations. This includes access to SCM functionality, ERP systems and decision support systems. Data and business logic are also independently stored.

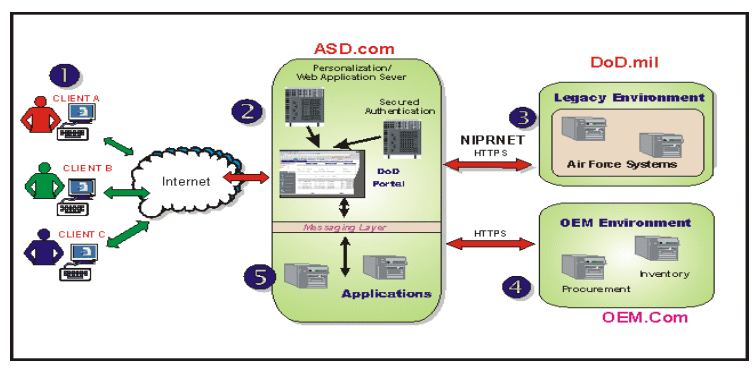

Figure 1. ISCM integration architecture [1]

The software architecture is mostly constructed in web-based environment that involves HTTP, server-side Java and XML. ISCM systems are generally no different than other business applications but still require some interfacing with old technologies such as aging ERPs and legacy systems [21].

\subsection{Benefits of ISCM systems}

ISCM delivers the enterprise with a competitive advantage by opening up opportunities to streamline processes, reduce costs, increase customer patronage, and more thorough planning abilities [19]. The benefits of ISCM systems are categorised into a number groups including financial, customer, planning, production, and implementation. Each of these groups is further discussed in the following subsections.

\subsubsection{Financial}

\section{Cost reduction}

In some manufacturing organisations, the cost of the supply chain can represent $60-80 \%$ of their total cost base [5]. One of the core benefits for driving efficiency through the supply chain is cost reduction. ISCM allows the organisation to maximize profitability through Reduced Customer Service, Administration and Inventory costs. Less staff are required to maintain the supply chain and order/inventory details can be made available to customers directly without human intervention [5] [8]. Some organisations have quoted $25 \%$ cost reductions per transaction, despite a $20 \%$ increase in orders [19].

\section{Quality financial information}

Another benefit is the improvement and reliability of financial information. ISCM systems maintain centralised databases, which are linked to other enterprise systems (eg. ERP, CRM) providing integrity, consistency and real-time 
data access to managers so that they can manage the supply chain with an organisational perspective [19].

\subsubsection{Customer}

\section{Retention}

Supply chain systems, through customer portals, provides customers with an instantaneous and holistic view of the progress of their transactions within the organisation. This level of service (coupled with benefits derived from Production) result in higher customer satisfaction levels and in turn, improve the firm's ability to attract new customers and importantly, retain them. Organisations have achieved Customer Service Levels of $97 \%$ following the introduction of ISCM systems. This retention translates into greater revenue. [3] [8] [5] [19].

\section{Behaviour}

The ability to capture customer transactions and preferences online, provides the organisation with the facility to track their behaviour and in turn, customise products \& services to cater for them [4].

\section{Promise}

Because of the level of workflow automation and inventory statistics, organisations are able to provide accurate estimates of when orders will be fulfilled at the time of ordering. This is known as 'capable-to-promise' (CTP) capability. This capability allows the organisation's customers to then plan more effectively [8].

\subsubsection{Planning}

Companies with ISCM systems have the ability to mathematically and graphically observe the performance of the supply chain giving the manager the power to "plan and make things happen" [19]. ISCM systems provide the organisation with the capabilities to derive more accurate demand planning with improved precision, create shorter planning and production cycles, establish one central data repository for the entire organisation and facilitate enhanced communications through rapid information dissemination [4] [8].

\subsubsection{Production}

ISCM provides the ability to holistically manage the supply chain allowing managers to dynamically respond to any situation that may arise so as to minimise its impact on production.

\section{Inventory Management}

By measuring the level of inventory and analysing turnover, supply chain systems can improve turnover by reducing the need for 'safety stocks' and the risk of retailer 'out-of-stocks'. Inventory items need to be consistently numbered to facilitate measurement and tracking. These benefits reduce the overhead required to store high inventory levels [5] [8]. Turner's [19] research claimed a $37 \%$ reduction in inventory levels as a result of ISCM implementation.

\section{Efficiency}

ISCM systems measure the performance of the supply chain through the generation of supply chain metrics. This allows process quality issues to be tracked and rectified, isolates bottlenecks in the process and measures lead times so that they can be aligned with available capacity to maximise plant utilisation. All of this ensures 'quicker time-to-market' for the firm's products. [5] [8].

Other efficiency benefits include no data rekeying through simplified automated order placement, order status inquiries, delivery shipment and invoicing [4] [8]. ISCM implementations have resulted in a $50 \%$ overtime reduction for some organisations [19].

\subsubsection{Implementation}

Consultants promise responsiveness and 'Plug \& Play' integrations. However, documented examples of supply chain failures by organisations such as Siemens AG, Nike, OPP Quimica and Shell are evidence that the implementation of ISCM systems is not as easy as vendors claim. Claims of "rapid integration" and "seamless linking" seem to significantly underestimate the effort required to integrate ISCM with the rest of the enterprise [13].

For Nike, "i2" ISCM software required a significant degree of customisation in order to integrate the software to the rest of the organisation. Customisation to enterprise software comes with great risk and significant cost for ongoing maintenance. Nike's summation of the software was that it "just didn't work". OPP Quimica (a Brazillian Chemicals Company) required the use of 3rd-party integration software in order to assimilate i2 to the rest of the enterprise architecture. Shell's implementation proved problematic with the need to tie 85 ERP sites to a single SCM platform [17].

\section{Issues and Barriers in ISCM Analysis}

Similar to the hype attached to Enterprise Resource Planning (ERP) applications, there has been significant customer backlash concerning the inability of software vendors to deliver easy integration and promised functionality [17]. Turner [19] believes that "few companies claim to have fully implemented SCM and have sustained the benefits proposed ISCM would create". In fact, Fontanella [7] indicates that only $25 \%$ of ISCM users are utilising the full suite of supply chain applications and that only $12 \%$ of users are receiving data from inbound suppliers and customers - far from an integrated supply chain.

Many of these issues stem from a failure to undertake thorough analysis in the following key areas.

- Focus on transaction systems over strategic systems to manage supply chains

Organisations are not taking a strategic view of ISCM systems. More so, they tend to only focus on transactions systems (eg. inventory control, order processing etc.), which provide little visibility of the 
enterprise [7] [19].

- Failure to pre-empt change to business processes In a majority of implementations, analysis has focused on the technical aspects of integrating ISCM systems with the remaining architecture. One area that has been neglected has been the effect on business processes. Organisations expect either staff to just "accept change" or "customise" the software both of these options are generally flawed. In order to reap the cost savings from ISCM systems, significant analysis must be conducted regarding process reengineering in order to ensure collaboration and continue to sustain benefits [7] [11] [19].

- Failure to appreciate geographical, relational, environmental considerations between buyer and supplier

The nature of ISCM (especially with multinational corporations), involves transacting across the world - "24 hours a day, 7 days per week, $360^{\circ}$ ". Analysts fail to appreciate the geographical, relational and environmental "inhibitors" for ISCM implementations of this scope [11].

- Cross-borders logistics, culture, language and economic \& regulatory climate are just some considerations which can affect the integration of business processes between regional offices \& external organisations, creating communication issues throughout the supply chain. One ill-performing participant in the supply chain will affect the performance of the entire supply chain [18].

- Failure to accurately identify the costs and benefits of ISCM implementation

Many implementations have been classed as failures because of ISCM systems perceived inability to reap benefits and produce cost savings as expected. However, in many cases, it is the initial analysis of cost and benefits that have been flawed. Because of the nature and scope of ISCM implementations, it is difficult to accurately quantify attributable cost reductions from ISCM because they could be derived throughout the supply chain and be complicated to calculate. In the same light, determining benefits share similar traits with some having the additional complication of being intangible (eg. benefits of a central database) and therefore, difficult to quantify [12].

- Insufficient Capability

The implementation and support of ISCM systems can be rather complex and therefore demands sophisticated resources and incremental implementations. Unfortunately, during the planning and analysis phases of implementation projects, organisations have failed to properly appreciate the level of complexity involved, resulting in significant under-resourcing. As a result, many organisations have suffered material cost overruns and delayed "go-live" times [7].

\section{Proposed Methodology for ISCM Systems}

\section{Analysis}

Due to the extent of failed ISCM system implementations, it is imperative to construct an appropriate analysis and development methodology, which can be adopted as the roadmap for enterprises flourishing in ISCM systems development and operations. The proposed methodology demonstrates an overall picture for constructing an ISCM system from recognising problems, analysing requirements to the implementation and operation, and it embraces seven phases:

1. Identifying information management structure

2. Identifying connecting components

3. Ensuring appropriate business processes

4. Establishing and developing interfaces

5. Developing new business processes

6. Confirm strategic alignment

7. Implementing ISCM systems

Following is a discussion and culmination of those seven phases within the proposed iterative framework.

\subsection{Identifying information management structure}

Given the global nature of supply chain systems and its level of required integration, a common ICT (information and communication technology) infrastructure must be able to extend around the globe, be able to support open and rapid communication, and to integrate easily with the architecture of not just the organisation, but also with the architecture of customers and suppliers. This will be conducive to information sharing.

The enterprise's information systems architecture must be properly analysed to ensure that it satisfies the needs of ISCM systems and can support security boundaries, hugely distributed database operations and event-driven applications. The architecture needs to be durable, flexible and embedded with the appropriate middleware in order to integrate as easy as possible [21]. It must also be sufficiently robust to cater for firewalls and other security measures, 24/7 global access and have redundant systems and processes to handle events when ISCM systems need to be offline for maintenance, emergency and recovery purposes.

In accordance with the criteria specified above, the Internet-based structure can be considered the most appropriate platform to satisfy these requirements. Nevertheless, participants in the supply chain have various capability and maturity levels in information management structure. Hence prior to adopt the Internet technology for integration, the existing information management structure of each participant must be determined.

\subsection{Identifying connecting components}

One of the most critical functions of supply chain management is to ensure the effective integration of 
information and material flows through the system. This includes understanding the value added to products and its related information flows (inputs and outputs) as it progresses through the supply chain [10]. This embraces analysis on the supply chain's real costs, and cost \& performance drivers [16].

Turner [19] identifies some of the key components, which need to be 'functionally' integrated. These components are also considered as the connecting components (or connecting business functions) between participants in the supply chain. These components include order management, customer service, invoicing, forecasting, distribution requirements planning (DRP), warehouse and inventory management, manufacturing planning, production control (MRPII) and integrated logistics.

\subsection{Ensuring appropriate business processes}

In order to enhance the supply chain processes, it is important to understand what happens currently. Generally supply chain processes may include the procurement, production, ordering, delivery and inventory paths, both within the company and external parties.

Firstly, analysts should analyse the supply chain processes and be able to appreciate the company's mix of products, end configurations, volumes, lifecycles, channels, customer segments and delivery outlets [20].

Each process should then be prioritised and broken down into its sub-processes, identifying each of its sources, outputs, transformations, timings, resources utilised and requirements. This would also be an opportune time to gather metrics concerning each of the processes in order to establish a baseline for identifying problems and to measure future process improvement.

Additionally any opportunities to benefit from "quick-wins" should be taken advantage of at this point [10].

\subsection{Establishing and Developing Interfaces}

Once architectural issues have been resolved and data requirements have been determined, a structure needs to be established to enable common linkages between both data providers and data recipients of the ISCM (ie. customers and suppliers) and linkages within ISCM processes. This will require the need to ascertain whether there are any missing links and determine how the data required will be sourced or provided and in which format.

The emerging technology for interface communications is XML (eXtensible Markup Language). XML uses HTML tags to enable the "definition, transmission, validation and interpretation of data". However, effort for this task should not be underestimated [21]. Significant resources may be required in analyzing sources from ERP and antiquated EDI systems. It has been suggested that 3 rd party interface tools (eg. Informatica \& Brio) can be used to ease the transition for these types of systems [21].

\subsection{Developing new business processes}

After conducting detail analysis of existing supply chain processes and identifying any inefficiencies and/or gaps in the process, a proposal should be created for the design of new processes. Not only should new processes cater for anticipated ISCM processing, but should be sufficiently visionary to accommodate for other strategic initiatives (CRM, Supplier Management, Knowledge Management).

The new supply chain should be modelled in a manner so that supply chain "blue prints" can be generated [21]. Tyndall et.al. [20] suggest an iterative approach to process design whereby a process is broken down into stages and then defined, analysed, executed, assessed and then re-defined. This cycle continues until the appropriate performance expectations have been achieved. This process can become quite complex and convoluted once organisations begin to incorporate back-end systems and the processes of other organisations.

Based on metrics determined during the initial business process review, goals should be set for process improvement.

\subsection{Confirm Strategic Alignment}

At the completion of most of the analytical work, It is important to revisit some of the groundwork that would have been completed during the planning phase activity in the traditional SDLC.

It has been included this framework to highlight the importance of ensuring an alignment between business strategy and expectations with the outcomes of the ISCM implementation - supply chain strategy is interdependent on the business strategic direction.

Analysts need to confirm that 'value' is being delivered through ISCM by conducting critical analysis on proposed benefits and costs to ensure that they are still realistic [20]. So as to prevent misalignment of resources and skillsets, analysts also need to confirm that the business problem can still be solved with its current complement of staff.

\subsection{Implementing ISCM systems}

This phase involves determining what activities will need to be undertaken to facilitate implementation of ISCM system - creating an action plan.

There are a number of factors should be considered in this final phase of the methodology such as setting up communication standards, developing business operation procedures, and establishing training programmes.

Furthermore, this phase should be expanded to incorporate activities that can assist in the detail analysis of implementation risk of the system. Conducting analysis in areas such as change management is one example. Inability to manage the implementation of change has been a key factor in project failure. Any enterprise systems place great strain on the organisation to adapt to 
reap the benefits. Change Management involves more than simply conducting user-training programmes, but involves a continuing consultative relationship with end users to secure buy-in.

\section{Conclusion and Future Challenge}

This paper endeavours to propose an analysis and development methodology for ISCM systems. The discussion started with review and investigation of the current ISCM solutions and architectures, and identified a number of benefits, issues and problems regarding to the implementation of ISCM systems. Based on the examination of existing ISCM status, the proposed methodology for ISCM systems analysis is constructed by a seven-phase development framework. The methodology tends to illustrate a systematic roadmap for enterprises in developing ISCM systems.

The future challenge for enterprises in operating and maintaining ISCM systems stressed on the overall maturity of technological availability and the flexibility of business processes aligning with the ISCM architecture.

\section{References}

[1] Advanced Software Design Inc. (2002). ASD supply chain solution [online]. ASD Global, Internet: http://www.asdglobal.com/products/dod.html (accessed 7/21/03)

[2] Armstrong E. (2002). The evolution of supply chain management software. Logistics Management, 41(9), pp.66-70.

[3] Bergert S, Kazimer-Shockley K. (2001). The customer rules. Intelligent Enterprise, Jul 23, 4(11), p31.

[4] Bragg S. (2002). 10 symptoms of poor supply chain performance [online]. ARC Advisory Group, Internet: http://www.idii.com/wp/arc_sc_perf.pdf (accessed 7/21/03).

[5] Cottrill K. (1997). Reforging the supply chain. Journal of Business Strategy, Nov-Dec 18(6), pp.35-39.

[6] Dalton G and Wilder C. (1998). eBusiness -- Global Links -Companies are turning to the Internet for tighter integration with suppliers overseas. Information Week, March 23, 674 pp.18-20.

[7] Fontanella J. (2001). The overselling of supply chain suites [online]. AMR Research, Internet: http://www.amrresearch.com/Content/view.asp?pmillid=662\&d ocid=8027 (accessed 7/21/03).

[8] Gledhill J. (2002). Create values with IT investment: how to generate a healthy ROI across the enterprise. Food Processing, Sept 63(9), pp.76-80.
[9] Handfield R. and Nichols Jr El. (1999). An introduction to supply chain management. Prentice Hall

[10] Michael-Donovan R. (2002). e-Supply chain management: Pre-requisites to success [online]. Performance Improvement, http://www.idii.com/wp/donovan_sc_part1.pdf (access 21/7/03) [11] Mol M. and Koppius O. (2002). Information technology and the internationalisation of the firm. Journal of Global Information Management. Oct-Dec, 10(4), pp.44-60.

[12] New S. (1994). A framework for analysing supply chain improvement [online]. Manchester School of Management UMIST, Internet: http://www.unf.edu/ ybolumol/tra_4202_011/Artiicles/sc_impr ovement.pdf (accessed 7/21/03)

[13] Oakton. (2003). Manufacturing and supply chain solutions [online]. Oakton Consulting, Internet: http://www.infact.com.au/clients/manufacturing.htm (accessed 7/21/03).

[14] OSD Comptroller iCenter (2002). Integrated supply chain management: Optimising logistics support [online]. Office of the Under Secretary of Defence, Internet: http://www.dod.mil/comptroller/icenter/learn/iscmconcept.pdf (accessed 7/21/03).

[15] Peoplesoft (2002). PeopleSoft supply chain management, PeopleSoft Inc.

[16] Seirlis A, (2001). Integrated Supply Chain Analysis [online]. TLB Consulting, Internet: http://www.tlb.co.za/library/comentary/intergrated.html (accessed 7/21/03).

[17] Smith T. (2002). Sharing the risk: How to avoid a supply-chain nightmare [online]. Internet Week.com, Internet: http://www.internetweek.com/supplyChain/INW20020725S000 7 (accessed 7/21/03).

[18] Strausl D. (2001). Four stages to building an effective supply chain network. EBN, Feb 26, p43.

[19] Turner (1993). Integrated Supply Chain Management: what's wrong with this picture? Industrial Engineering, Dec, 25(12), pp.52-55.

[20] Tyndall G et. al. (2002). Making it happen: The value producing supply chain [online]. Centre for Business Innovation - Ernst \& Young, Internet: http://www.cbi.cgey.com/journal/issue3/features/makin/makin. pdf (accessed 7/21/03).

[21] Zieger A. (2001). Preparing for supply chain architectures [online]. PeerToPeerCentral.com, Internet: http://www-106.ibm.com/developerworks/web/library/wa-supc h.html?dwzone=web (accessed 7/21/03). 